\title{
Desrama, crescimento e predisposição à podridão-do-lenho em Acacia mangium
}

\author{
Helio Tonini(1) e Bernardo de Almeida Halfeld-Vieira( ${ }^{(1)}$
}

\author{
(1)Embrapa Roraima, BR 174, Km 8, Caixa Postal 133, CEP 69301-970 Boa Vista, RR. E-mail: helio@cpafrr.embrapa.br, \\ halfeld@cpafrr.embrapa.br
}

\begin{abstract}
Resumo - A desrama é um procedimento que aumenta o valor e a qualidade da madeira. Entretanto, se realizada de forma inadequada pode reduzir o crescimento e constituir fator de predisposição à podridão-do-lenho. O objetivo deste trabalho foi estudar o efeito da intensidade e época da desrama sobre o crescimento inicial e incidência de árvores com ferimentos não cicatrizados de Acacia mangium. Foi instalado um experimento em delineamento de blocos ao acaso, com três repetições e cinco tratamentos: testemunha (sem desrama); desrama de troncos múltiplos e galhos a 50 e 70\% da altura, em época de baixa e alta pluviosidade. As avaliações de crescimento e presença de ferimentos não cicatrizados foram feitas seis meses depois da aplicação dos tratamentos. A época e a intensidade de desrama, quando efetuadas aos 8 e 13 meses, não afetaram o crescimento em diâmetro e altura. Houve boa cicatrização de ferimentos em árvores desramadas oito meses depois do plantio, em época de baixa pluviosidade, independentemente da intensidade. Árvores desramadas aos 13 meses depois do plantio, em época de alta pluviosidade, demonstraram predisposição à podridão-do-lenho.
\end{abstract}

Termos para indexação: Racosperma mangium, diâmetro, altura, doença, manejo florestal.

\section{Pruning on growth and heartrot predisposing in Acacia mangium}

\begin{abstract}
Pruning increases quality and economic value of the wood. Inadequate pruning procedures, however, interfere negatively on growth and consist on a predisposing factor to heartrot. The objective of this work was to investigate the effect of intensity and season of pruning on initial growth and on incidence of Acacia mangium trees with non-occluded wounds. The experimental design was in randomized blocks with three replicates and five treatments: control (without pruning); pruning and singling at 50 and $70 \%$ of total height, in low and high precipitation season. Growth evaluations and the presence of non-occluded wounds were performed six months after treatments application. The season and intensity of pruning operations did not influence height and diameter growth. Efficient wound occlusion occurred in trees pruned eight months after planting in low precipitation season, with no intensity effect. On trees pruned 13 months after planting, in high precipitation season, trees predisposed to heartrot were observed.
\end{abstract}

Index terms: Racosperma mangium, DBH, height growth, wood rot, disease, forest management.

\section{Introdução}

A Acacia mangium Willd. [sin. Racosperma mangium (Willd.) Pedley] é a espécie florestal mais plantada no mundo, com uma área comercialmente explorada de aproximadamente 600 mil hectares. Atualmente, é a mais utilizada no Sudeste Asiático, principalmente na Indonésia e na Malásia (Galiana et al., 2002).

Nativa do norte do Estado de Queensland, na Austrália, Papua Nova Guiné e ilhas de Irian Java e Molucas, na Indonésia, é considerada de rápido crescimento e vida curta - 30 a 50 anos de idade -, adaptada a uma larga faixa de solos ácidos, pH 4,5-6,5, pouco adaptada, porém, a solos calcários (Jøker, 2000).
Em Roraima, A. mangium foi introduzida no final da década de 90, com o objetivo de avaliar seu crescimento em condições edafoclimáticas de savana. A partir de 1999, começaram a ser realizados plantios comerciais visando a suprir a necessidade de matéria-prima para indústria de produtos serrados e celulose, ocupando atualmente uma área de cerca de 21.500 ha.

A madeira de $A$. mangium pode ser utilizada para celulose, compensados, laminados e produtos serrados (Clark et al., 1991). Quanto à utilização em produtos serrados e laminados, são necessários tratamentos silviculturais, que melhorem a qualidade da madeira, como a desrama. 
O valor e a utilidade da madeira de povoamentos manejados são reduzidos, principalmente pelos nós e pelas distorções da grã, por eles causados (Hawley \& Smith, 1972). Os nós depreciam a qualidade da madeira em razão da presença de grã irregular nas suas proximidades que, no caso de compressão paralela às fibras, farão a madeira comportar-se com instabilidade. Esta descontinuidade ainda pode afetar peças sujeitas à flexão e à contração desigual dos tecidos dos nós durante a secagem, que origina deformações indesejáveis (Burger \& Richter, 1991).

A desrama é um procedimento que aumenta o valor comercial e a qualidade da madeira (Schneider, 1999), porém, se realizada de forma inadequada, pode reduzir o crescimento, pela perda assimilatória ocasionada pela forte remoção da copa verde ou por danos bióticos causados por fungos.

Em razão de a $A$. mangium não apresentar desrama natural eficiente e possuir tendência a formar troncos múltiplos, esse procedimento, nos estágios iniciais, é considerado uma prática de manejo necessária, visando à melhoria da qualidade da madeira e à formação de fustes longos de grandes dimensões (Tuomela et al., 1996).

A maioria das espécies florestais possui mecanismos fisiológicos eficientes para reduzir traumas. Esses mecanismos se realizam mediante reações químicas que criam barreiras, impedindo a entrada de fungos e outros patógenos (Schwarze et al., 2000; Ferreira \& Milani, 2002). A redução do crescimento, depois de uma desrama forte, pode afetar o tempo de oclusão dos ferimentos, que resulta em aumento do risco de invasão por patógenos e perda da dominância, ocasionando desvantagem na competição por luz em um povoamento florestal (Montagu et al., 2003).

A desrama em épocas de baixa pluviosidade pode ser uma forma de reduzir o risco de incidência de podridões-do-lenho, pois há indícios da influência de condições de alta umidade na invasão por patógenos (See \& Arentz, 1997). Por sua vez, fatores de estresse, como o deficit hídrico, podem contribuir para a predisposição a doenças relacionadas ao processo de declínio (Manion, 2003). Outro aspecto a ser considerado é a velocidade da oclusão de ferimentos, influenciada pelo diâmetro dos ramos e vigor vegetativo (Schwarze et al., 2000; Montagu et al., 2003).

A. mangium é altamente suscetível à podridão-dolenho ou cerne, que está relacionada à permanência de galhos mortos na planta e à presença de ferimentos, o que propicia a invasão do complexo de fungos que causa a podridão-do-lenho (Schwarze et al., 2000; See, 2002; Barry et al., 2004; Lee, 2004). A presença de ferimentos tem sido considerada fator importante, pois
A. mangium tem dificuldade em formar uma zona de proteção efetiva (Schmitt et al., 1995).

Ito \& Nanis (1997), ao avaliar o efeito da desrama na incidência de podridão-do-lenho de A. mangium na Malásia, sugerem que a primeira desrama seja feita em árvores jovens, com galhos pequenos e vivos.

No Brasil, Halfeld-Vieira et al. (2006) relataram pela primeira vez a podridão-do-lenho em $A$. mangium, ocasionando perdas significativas. A existência de grandes áreas plantadas com A. mangium em Roraima, em florestas destinadas ao uso em produtos serrados, torna necessário o desenvolvimento de sistemas silviculturais que possibilitem melhorar a qualidade da madeira e reduzir perdas decorrentes da podridão-do-lenho.

O objetivo deste trabalho foi avaliar o efeito da intensidade e época da desrama no crescimento inicial e na incidência de árvores com ferimentos não cicatrizados que possam constituir fator de predisposição à podridão-do-lenho em povoamentos de A. mangium.

\section{Material e Métodos}

O experimento foi instalado na Fazenda Araçá, da Empresa Ouro Verde Agrossilvopastoril, no Município do Cantá, RR, cujas coordenadas geográficas são $2^{\circ} 43^{\prime} \mathrm{N}$ e $60^{\circ} 12^{\prime} \mathrm{W}$.

De acordo com a classificação de Köppen, o clima na região é do tipo Awi, tropical chuvoso com predomínio de savanas. A precipitação média anual nesta região varia entre 1.440 e $1.660 \mathrm{~mm}$. As maiores precipitações ocorrem em maio, junho e julho e chegam a concentrar mais de 56\% do total anual. As menores precipitações ocorrem entre setembro e fevereiro, com cerca de $21 \%$ da precipitação anual (Mourão Júnior et al., 2003).

Os principais tipos de solos presentes nessa região são os Latossolos e Argissolos Amarelos e VermelhoAmarelos. De maneira geral, são predominantemente cauliníticos, distróficos e álicos, com alguns problemas físicos - solos com coesão e problemas de drenagem (Melo et al., 2003). A vegetação é do tipo savana, com fisionomia campestre e árvores isoladas de pequeno porte, que se adensam próximo aos cursos de água com relevo levemente ondulado, de acumulação quaternária (Brasil, 1975).

O plantio foi realizado em junho de 2003 e o preparo do solo consistiu em destoca e escarificação a $60 \mathrm{~cm}$, seguida de uma gradagem a $40 \mathrm{~cm}$, sem adubação na cova, e adubação de cobertura aos cinco meses depois do plantio, com 150 g de Yorim Master, com 17,5\% de $\mathrm{P}_{2} \mathrm{O}_{5}, 20 \%$ de Ca, $7 \%$ de $\mathrm{Mg}, 0,55 \%$ de $\mathrm{Zn}, 0,1 \%$ de $\mathrm{B}, 0,12 \%$ de $\mathrm{Mn}$, $0,006 \%$ de $\mathrm{Mo}$ e $0,05 \%$ de $\mathrm{Cu}$. O espaçamento adotado foi o de $3,6 \times 3,0 \mathrm{~m}$. 
O experimento foi instalado em fevereiro de 2004. O delineamento experimental utilizado foi o de blocos ao acaso, com cinco tratamentos e três repetições. Os tratamentos foram: testemunha (sem desrama e sem remoção de troncos múltiplos); remoção de troncos múltiplos e desrama a 50\% da altura total, em época de baixa pluviosidade (fevereiro); remoção de troncos múltiplos e desrama a $70 \%$ da altura total, em época de baixa pluviosidade; remoção de troncos múltiplos e desrama a $50 \%$ da altura total, em época de alta pluviosidade (julho); remoção de troncos múltiplos e desrama a 70\% da altura total, em época de alta pluviosidade. As unidades amostrais possuíram as dimensões de 33x21 m, com bordaduras de duas linhas de árvores, totalizando 25 árvores úteis por parcela. As avaliações foram feitas em duas ocasiões, seis meses depois da aplicação dos tratamentos: a primeira, em agosto de 2004, e a segunda, em fevereiro de 2005, aos 14 e 19 meses depois do plantio, respectivamente.

Todas as árvores úteis tiveram a CAP (circunferência tomada a $1,30 \mathrm{~m}$ do solo) e a altura total medidas. As circunferências foram medidas com fita métrica e as alturas com hipsômetro Blume-Leiss. O DAP (diâmetro tomado a 1,30 m do solo) foi obtido dividindose o valor da CAP por 3,1416. A predisposição à podridão-do-lenho foi avaliada por contagem do número de árvores com ferimentos cicatrizados e não cicatrizados, ocasionados pela desrama, seis meses depois da aplicação dos respectivos tratamentos. Na análise, foram utilizados os valores de incidência.

As análises estatísticas dos ensaios para avaliação do crescimento em altura e diâmetro foram realizadas em esquema fatorial, considerando duas épocas de desrama $x$ duas intensidades mais uma testemunha, e teste de médias, para cada fator, por diferença mínima significativa $(\mathrm{p}<0,05)$ (Fisher-LSD) (Nashimoto \& Wright, 2005). Quanto à incidência de árvores com ferimentos não cicatrizados, foi realizado contraste entre as médias das duas épocas de poda e duas intensidades de poda. Nas análises, utilizou-se o programa SAS, versão 8, utilizando o proc GLM (SAS Institute, 2001).

\section{Resultados e Discussão}

Não houve diferença quanto ao crescimento em diâmetro e altura, na primeira avaliação, aos 14 meses depois do plantio.

Na segunda avaliação, aos 8 e 13 meses depois do plantio, a análise de variância referente ao crescimento em diâmetro das árvores de A. mangium, submetidas a diferentes intensidades de desrama, indicou que a intensidade não teve influência significativa sobre o crescimento (Tabela 1). Quanto ao crescimento em altura, a dife- rença detectada pela análise de variância (Tabela 2) não foi comprovada pelo teste de médias (Tabela 3). O teste de médias empregado não exige a prévia significância do teste F (Storck et al., 2000).

Este resultado não concorda com os obtidos por Majid \& Paudyal (1992) e Tuomela et al. (1996), que verificaram redução no incremento em diâmetro e no crescimento volumétrico, aos quatro anos de idade, sempre que a remoção da copa foi superior a $40 \%$ da altura, não sendo recomendada a remoção de troncos múltiplos e de galhos aos oito meses de idade, para manter altas taxas de crescimento.

A presença de ferimentos com a exposição do lenho é um indicativo da predisposição à podridão-do-lenho em A. mangium. Realizando-se cortes transversais nos nós de árvores da bordadura, na última avaliação, foi verificado início de degradação do lenho, originados de ferimentos não cicatrizados, provenientes da operação de desrama, em árvores que foram desramadas 13 meses depois do plantio. A presença de zona de reação e efetiva compartimentalização (Schwarze et al., 2000; Ferreira

Tabela 1. Análise de variância para efeito da desrama no crescimento em diâmetro, na segunda avaliação, 19 meses depois do plantio. Coeficiente de variação de 8,58\%.

\begin{tabular}{lccccc}
\hline Causa da variação & GL & SQ & QM & F & p \\
\hline Bloco & 2 & 1,5967 & 0,7983 & 8,28 & 0,0076 \\
Intensidade de desrama & 2 & 0,1304 & 0,0652 & 0,68 & 0,5303 \\
Época da desrama & 1 & 0,0544 & 0,0544 & 0,56 & 0,4697 \\
Intensidade x época & 2 & 0,0874 & 0,0437 & 0,45 & 0,6480 \\
Resíduo & 10 & 0,9644 & 0,0964 & - & - \\
\hline
\end{tabular}

Tabela 2. Análise de variância para efeito da desrama no crescimento em altura, na segunda avaliação, 19 meses depois do plantio. Coeficiente de variação de 9,86\%.

\begin{tabular}{lccccc}
\hline Causa da variação & GL & SQ & QM & F & p \\
\hline Bloco & 2 & 1,8242 & 0,9121 & 4,95 & 0,0320 \\
Intensidade de desrama & 2 & 2,9862 & 1,4931 & 8,11 & 0,0081 \\
Época da desrama & 1 & 0,0533 & 0,0533 & 0,29 & 0,6021 \\
Intensidade x época & 2 & 0,0800 & 0,0400 & 0,22 & 0,8084 \\
Resíduo & 10 & 1,8411 & 0,1841 & - & - \\
\hline
\end{tabular}

Tabela 3. Contraste entre médias para altura na segunda avaliação, 19 meses depois do plantio ${ }^{(1)}$.

\begin{tabular}{cccc}
\hline & $\mathrm{I} 0$ & $\mathrm{I} 1$ & $\mathrm{I} 2$ \\
\hline $\mathrm{E} 1$ & $4,92 \mathrm{Aa}$ & $4,18 \mathrm{Aa}$ & $4,14 \mathrm{Aa}$ \\
$\mathrm{E} 2$ & $4,92 \mathrm{Aa}$ & $4,21 \mathrm{Aa}$ & $3,84 \mathrm{Aa}$ \\
\hline
\end{tabular}

(1)Médias seguidas da mesma letra, maiúscula na linha e minúscula na coluna, não diferem entre si a 5\% de probabilidade; I0: testemunha (sem desrama); I1: desrama de troncos múltiplos e galhos a $50 \%$ da altura total; I2: desrama de troncos múltiplos e galhos a $70 \%$ da altura total; E1: desrama de troncos múltiplos e galhos em época de baixa pluviosidade, oito meses depois do plantio; E2: desrama de troncos múltiplos e galhos em época de alta pluviosidade, 13 meses depois do plantio. 
\& Milani, 2002) foi verificada em ferimentos cicatrizados nas árvores desramadas oito meses depois do plantio (Figura 1). Ocorreu cicatrização de todos os ferimentos em plantas desramadas aos oito meses depois do plantio, independentemente da intensidade da desrama. Por sua vez, na realização da desrama aos 13 meses depois do plantio, observa-se alta incidência
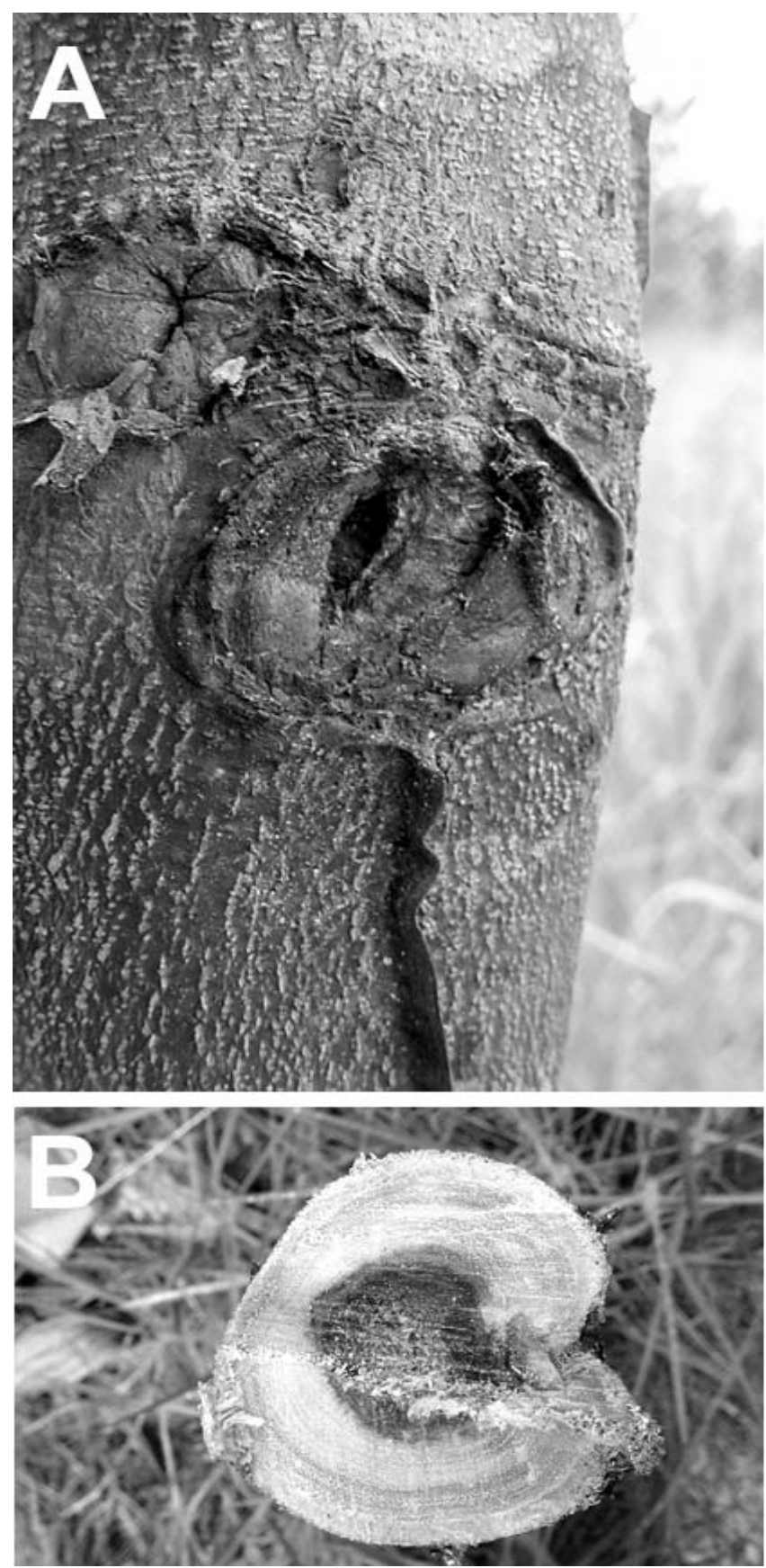

de árvores com ferimentos não cicatrizados, não havendo distinção entre árvores desramadas a 50 ou 70\% da altura (Tabela 4).

Estes resultados corroboram as conclusões de Ito \& Nanis (1997), que verificaram alto porcentual de árvores com podridão-do-lenho, a partir de ferimentos não cicatrizados devido à desrama, e recomendaram a
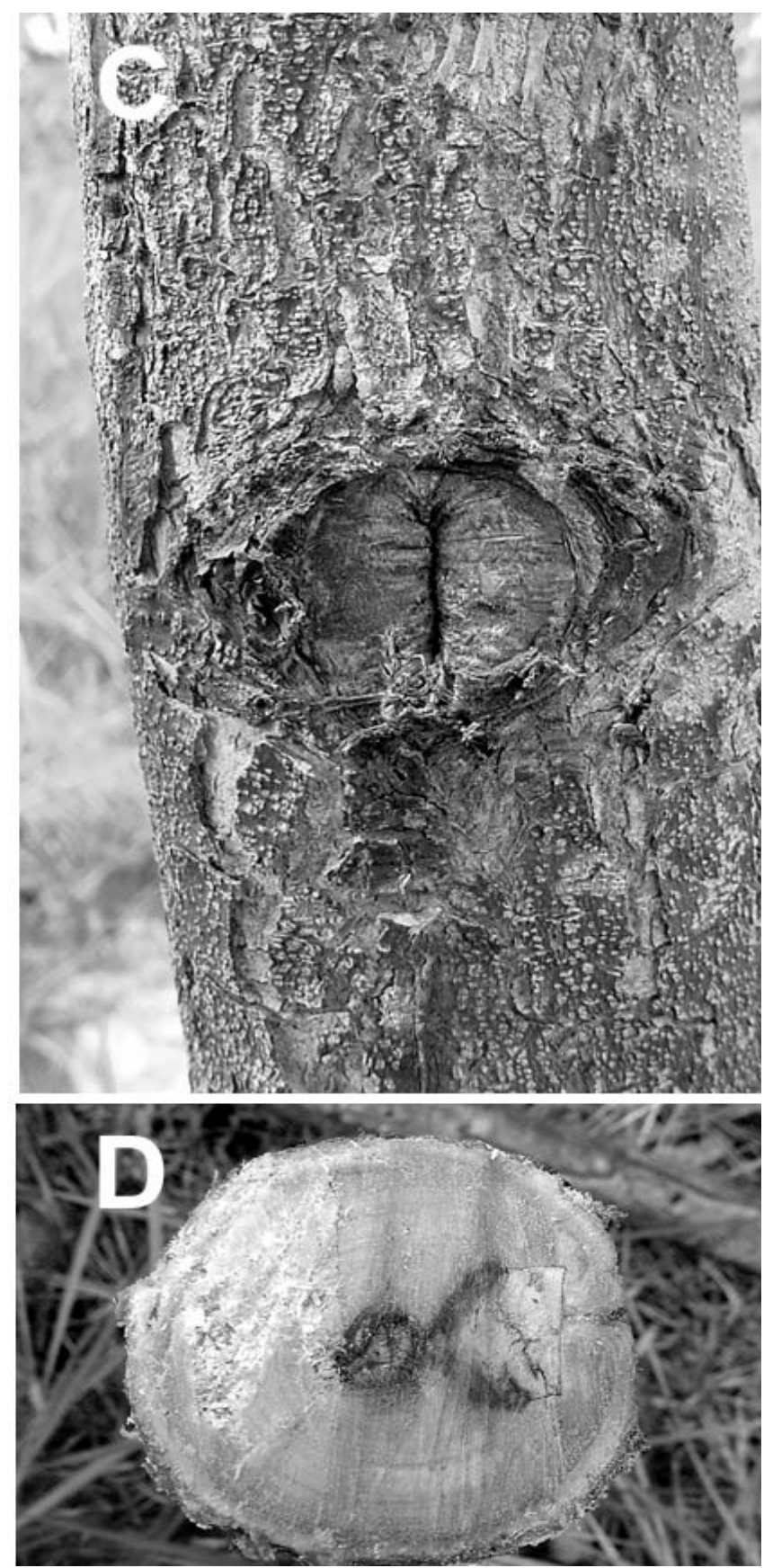

Figura 1. Ferimento de desrama não cicatrizado (A) e respectiva seção transversal, mostrando início de podridão-do-lenho, atingindo o cerne (B); ferimento de poda cicatrizado (C) e respectiva seção transversal, mostrando zona de reação, com efetiva compartimentalização do ferimento (D). 
Tabela 4. Contraste entre médias para incidência de árvores com ferimentos não cicatrizados, indicando predisposição à podridão-do-lenho, em avaliação seis meses depois da desrama $^{(1)}$.

\begin{tabular}{ccc}
\hline & $\mathrm{I} 1$ & $\mathrm{I} 2$ \\
\hline $\mathrm{E} 1$ & $0,0 \mathrm{Ab}$ & $0,0 \mathrm{Ab}$ \\
$\mathrm{E} 2$ & $16,3 \mathrm{Aa}$ & $17,7 \mathrm{Aa}$ \\
\hline
\end{tabular}

(1)Médias seguidas da mesma letra, maiúscula na linha e minúscula na coluna, não diferem entre si a 5\% de probabilidade; I1: desrama de troncos múltiplos e galhos a 50\% da altura total; I2: desrama de troncos múltiplos e galhos a $70 \%$ da altura total; E1: desrama de troncos múltiplos e galhos em época de baixa pluviosidade, oito meses depois do plantio; E2: desrama de troncos múltiplos e galhos em época de alta pluviosidade, 13 meses depois do plantio.

realização da desrama em ramos vivos e com pequeno diâmetro. Deve-se considerar também a época em que as operações foram realizadas. Segundo See \& Arentz (1997), condições de umidade relativa continuamente alta, favorecem a colonização por fungos do complexo apodrecimento do lenho, principalmente quando há oclusão incompleta dos ferimentos. O período de menor pluviosidade parece não influenciar a predisposição à podridão-do-lenho em árvores jovens submetidas à desrama em época seca.

Uma vez que a A. mangium apresenta tendência a formar troncos múltiplos e propensão ao ataque de fungos nas condições estudadas, a desrama em idades jovens é necessária, pois, quanto maior a idade, maior a dimensão dos galhos e o tempo de oclusão, aumentando a chance de ocorrência de podridão-do-lenho.

A necessidade de se fazer a desrama, para que se obtenha aumento de qualidade e valor dos povoamentos, e o fato de não haver diferença no crescimento em diâmetro e altura em função da época e intensidade da desrama indicam que o mais adequado é eliminar os galhos e troncos múltiplos que ocorrem abaixo da altura referente a $70 \%$ da altura total, na primeira intervenção. Este procedimento oferece duas vantagens: otimiza a utilização da mão-de-obra e reduz a propensão à podridão-do-lenho.

\section{Conclusões}

1. A época e a intensidade da desrama em árvores de Acacia mangium, efetuadas aos 8 e 13 meses depois do plantio, não exercem efeito sobre o crescimento inicial em diâmetro e altura.

2. A desrama em plantas de Acacia mangium aos oito meses, em época de baixa pluviosidade, ocasiona boa cicatrização de ferimentos e menor incidência de árvores com predisposição à podridão-do-lenho, ao con- trário da desrama em árvores aos 13 meses, em época de alta pluviosidade.

\section{Agradecimentos}

Aos técnicos da Ouro Verde Agrosilvipastoril e a Giovanni Ribeiro de Souza, pelo apoio.

\section{Referências}

BARRY, K.M.; IRIANTO, R.S.B.; SANTOSO, E.; TURJAMAN, M.; WIDYATI, E.; SITEPU, I.; MOHAMMED, C.L. Incidence of heartrot in harvest-age Acacia mangium in Indonesia, using a rapid survey method. Forest Ecology and Management, v.190, p.273280, 2004.

BRASIL. Ministério das Minas e Energia. Projeto Radambrasil. Folha NA.20 Boa Vista e parte das folhas NA.21 Tumucumaque, NB.20 Roraima e NB.21: geologia, geomorfologia, pedologia, vegetação e uso potencial da terra. Rio de Janeiro, 1975. 428p. (Levantamento de recursos naturais, 8).

BURGER, L.M.; RICHTER, H.G. Anatomia da madeira. São Paulo: Nobel, 1991. 154p.

CLARK, N.B.; BALODIS, V.; FANG, G.; WANG, J. Pulping properties of tropical acacias. In: TURNBULL, J.W. (Ed.). Advances in tropical Acacia research: proceedings of an international workshop held in Bangkok. Canberra, ACT: Australian Centre for International Agricultural Research, 1991. p.138-144.

FERREIRA, F.A.; MILANI, D. Diagnose visual e controle das doenças abióticas e bióticas do eucalipto no Brasil. Mogi Guaçu: International Paper, 2002. 98p.

GALIANA, A.; BALLE, P.; KANGA, A.N.G.; DOMENACH, A.M. Nitrogen fixation estimated by the ${ }^{15} \mathrm{~N}$ natural abundance method in Acacia mangium Willd. inoculated with Bradyrhizobium sp. and grown in silvicultural conditions. Soil Biology and Biochemistry, v.34, p.251-262, 2002.

HALFELD-VIEIRA, B.A.; MOURÃO JÚNIOR, M.; TONINI, H.; NECHET, K.L. Podridão-do-lenho em plantios homogêneos de Acacia mangium. Pesquisa Agropecuária Brasileira, v.41, p.709-711, 2006.

HAWLEY, R.C.; SMITH, D.M. Silvicultura prática. Barcelona: Omega, 1972. 192p.

ITO, S.; NANIS, L.H. Survey of heart rot on Acacia mangium in Sabah, Malaysia. Japan Agricultural Research Quaterly, v.31, p.65-71, 1997.

JØKER, D. Acacia mangium Willd. Humlebaek: Danida Forest Seed Centre, 2000. 2p. (Seed leaflet, 3).

LEE, S.S. Diseases and potential threats to Acacia mangium plantations in Malaysia. Unasylva, v.55, p.31-35, 2004.

MAJID, N.M.; PAUDYAL, B.K. Pruning trial for Acacia mangium Willd. plantation in Peninsular Malaysia. Forest Ecology and Management, v.47, p.285-293, 1992.

MANION, P.D. Forest pathology for the last century: a retrospective and directions for the future. Phytopathology, v.93, p.1052-1055, 2003. 
MELO, V.F.; GIANLUPPI, D.; UCHÔA, S.C.P. Características edafológicas dos solos do Estado de Roraima. Boa Vista: Embrapa Roraima, 2003. 33p.

MONTAGU, K.D.; KEARNEY, D.E.; SMITH, R.G.B. The biology and silviculture of pruning planted eucalypts for clear wood production - a review. Forest Ecology and Management, v.179, p.1-13, 2003.

MOURÃO JÚNIOR, M.; XAUD, H.A.M.; OLIVEIRA JÚNIOR, J.O.L.; MOURA NETO, M.A.; SMIDERLE, J.O.; PEREIRA, P.R.V.; GIANLUPPI, V. Precipitação pluviométrica em áreas de savana de Roraima: campos experimentais Monte Cristo e Água Boa. Boa Vista: Embrapa Roraima, 2003. 6p.

NASHIMOTO, K.; WRIGHT, F.T. Multiple comparison procedures for detecting differences in simply ordered means. Computational Statistics and Data Analysis, v.48, p.291-306, 2005.

SAS INSTITUTE (Cary, Estados Unidos). SAS/OR user's guide: statistics, version 8. Cary, 2001. 1028p.

SCHMITT, U.; LIESE, W.; THONG, H.L.; KILLMANN, W. The mechanisms of wound response in Acacia mangium. IAWA Journal, v.16, p.425-432, 1995.
SCHNEIDER, P.R.; FINGER, C.A.G.; HOPPE, J.M. Efeito da intensidade de desrama na produção de Pinus elliottii Engelm., implantados em solo pobre, no Estado do Rio Grande do Sul. Ciência Florestal, v.9, p.35-46, 1999.

SCHWARZE, W.M.R.; ENGELS, J.; MATTHECK, C. Fungal strategies of wood decay in trees. Berlin: Springer-Verlag, 2000. 185p.

SEE, L.S. Overview of the heartrot problem in acacia-gap analysis and research opportunities. In: BARRY, K. (Ed.). Heartrots in plantation hardwoods in Indonesia and Australia. Canberra: CSIRO Publishing, 2002. p.26-34.

SEE, L.S.; ARENTZ, F. A possible link between rainfall and heart rot incidence in Acacia mangium? Journal of Tropical Forest Science, v.9, p.441-448, 1997.

STORCK, L.; GARCIA, D.C.; LOPES, S.J.; ESTEFANEL, V. Experimentação vegetal. Santa Maria: UFSM, 2000. 198p.

TUOMELA, K.; OTSAMO, A.; KUUSIPALO, J.; VUOKKO, R.; NIKLES, G. Effect of provenance variation and singling and pruning on early growth of Acacia mangium Willd. plantation on Imperata cylindrica (L.) Beauv. dominated grassland. Forest Ecology and Management, v.84, p.241-249, 1996.

Recebido em 12 de agosto de 2005 e aprovado em 20 de março de 2006 